\title{
KONTRIBUSI TENAGA KERJA INDONESIA TERHADAP KONDISI EKONOMI RUMAH TANGGA DI DESA JEROWARU NTB
}

\author{
Yunan Heri ${ }^{1}$, I Putu Sriartha ${ }^{2 *}$ \\ Program Studi Pendidikan Geografi, Universitas Pendidikan Ganesha, Singaraja, Indonesia
}

\author{
A R T I C L E I N F O \\ Article history: \\ Received 11 April 2019 \\ Received in revised form \\ 15 Mei 2019 \\ Accepted 12 Juli 2019 \\ Available online 31 Agustus \\ 2019 \\ Kata Kunci: \\ TKI \\ ekonomi rumah tangga \\ remitan \\ Keywords: \\ Migrant Workers \\ Household Economics \\ Remittances
}

\begin{abstract}
A B S T R A K
Penelitian ini dilaksanakan di Desa Jerowaru NTB bertujuan: (1) mengidentifikasi kondisi ekonomi TKI ke Malaysia asal Desa Jerowaru Kabupaten Lombok Timur; (2) mengidentifikasi faktor-faktor yang mendorong TKI asal Desa Jerowaru untuk mengadakan mobilitas sebagai tenaga kerja ke Malaysia; (3) menganalisis kontribusi (remitan) TKI ke Malaysia asal Desa Jerowaru terhadap ekonomi keluarga/rumah tangga di daerah asal. Rancangan yang digunakan dalam penelitian ini adalah deskriptif. Hasil penelitian menunjukan: 1) Kondisi ekonomi TKI asal Desa Jerowaru ke Malaysia setelah bekerja menjadi TKI, terjadi peningkatan yang singnifikan terutama dilihat dari keadaan fisik rumah, yakni meningkatnya kepemilikan rumah berlantai keramik. 2) Faktor yang mendorong TKI asal Desa Jerowaru untuk melakukan mobilitas sebagai TKI ke Malaysia adalah didominasi oleh tidak adanya biaya untuk sekolah bagi anak-anaknya sebesar $35 \%$. 3) Kontribusi (remitan) TKI ke Malaysia terkatagori sedang yaitu 74,1 \% yang dipergunakan untuk keperluan rumah tangga dan kehidupan sehari-hari.
\end{abstract}

\section{A B S T R A C T}

The research was carried out in the Jerowaru Village of NTB aimed at: (1) identify the economic conditions of Indonesian migrant workers to Malaysia from Jerowaru Village, East Lombok Regency; (2) identify the factors that encourage migrant workers from Jerowaru Village to conduct mobility as workers to Malaysia; (3) analyze the contribution (remittances) of migrant workers to Malaysia from Jerowaru Village to the family/household economy in the area of origin. The research in this study used descriptive. The results showed: 1) The economic conditions of migrant workers from Jerowaru Village to Malaysia after successfully becoming migrant workers, there was a significant increase in terms of the physical condition of the house, as was the case with ceramic tile house ownership. 2) The factor driving TKI from Jerowaru Village to do mobility as migrant workers to Malaysia is related to the absence of fees for schooling for children by 35\%. 3) The contribution (remittance) of Indonesian migrant workers to Malaysia is categorized as moderate, namely $74.1 \%$ which is used for household needs and daily life.

\footnotetext{
* Corresponding author.

E-mail addresses: yunanheri0105@gmail.com, putusriartha@gmail.com
} 


\section{Pendahuluan}

Undang-Undang Dasar 1945 pasal 27 menyatakan bahwa "tiap-tiap warga negara berhak atas pekerjaan dan penghidupan yang layak bagi kemanusiaan". Dengan demikian penciptaan kesempatan kerja merupakan masalah mendasar bagi kehidupan bangsa Indonesia. Kesempatan kerja tidak hanya mempunyai arti ekonomi, tetapi juga mempunyai arti kemanusiaan, yaitu menumbuhkan harga diri. Ini mempertegas bahwa setiap upaya pembangunan harus diarahkan pada penciptaan lapangan kerja, sehingga setiap warga negara dapat memperoleh pekerjaan dan menuju kehidupan yang layak bagi kemanusiaan.

Dari apa yang tertuang di atas dapat diambil suatu makna bahwa manusia merupakan titik pusat dari segala pembangunan dan juga merupakan sasaran pembangunan yang ingin dibangun harkat dan martabatnya. Disisi lain manusia adalah semberdaya pembangunan yang paling utama diantara sumber-sumberdaya lain yang harus terus dibangun kemampuan dan kekuatannya sebagai pelaksana dan penggerak pembangunan. Dalam konteks ini pembangunan tenaga kerja mempunyai arti strategis, karena manusia sebagai pelaksana dan penggerak dalam pembagunan di Indonesia. Angkatan kerja yang produktif (umur 20 - 40 tahun) merupakan akar terbentuknya manusia mandiri, manusia yang dapat menolong dirinya sendiri serta mambangun keluarga sejahtera (Ananta, 1995 : 25). Telah banyak dikemukakan oleh berbagai kalangan bahwa masalah ketenagakerjaan di Indonesia merupakan masalah nasional yang berkepanjangan sejak orde baru sampai sekarang. Dalam pengamalan pelaksanaan pembangunan selama ini, terlihat nyata bahwa pertumbuhan angkatan kerja yang cukup pesat kurang diimbangi dengan penciptaan kesempatan kerja sehingga terjadi pengangguran yang berakumulasi setiap tahun dan dapat dilihat pada Gambar 1 .

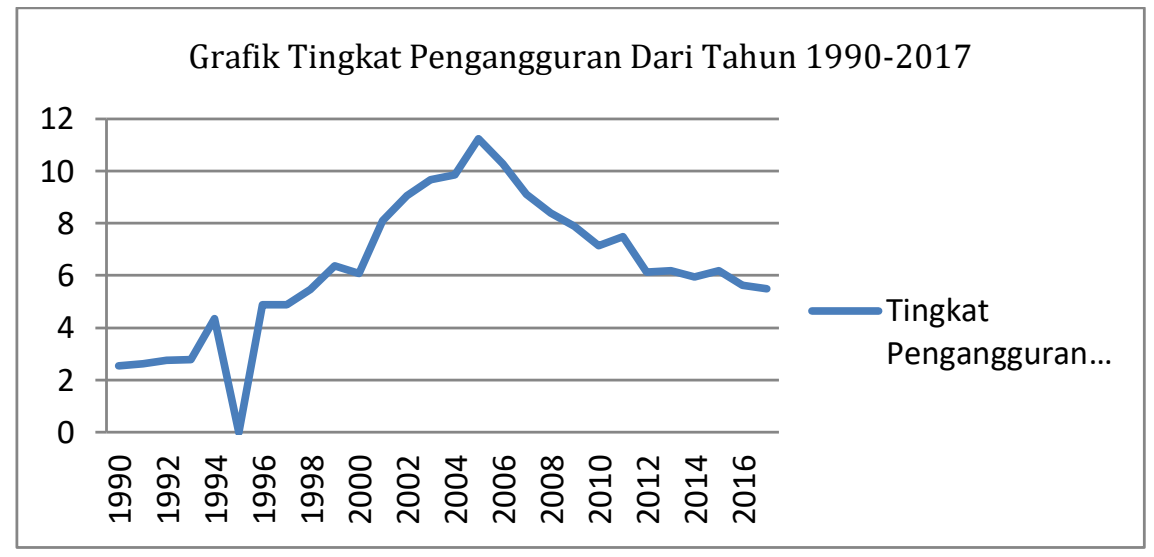

Gambar 1. Tingkat Pengangguran di Indonesia dari Tahun 1990-2017

Peraturan Mentri Tenaga Kerja dan Transmigrasi Republik Indonesia No 12 Tahun 2012 menggariskan suatu kebijakan tentang rencana pembangunan jangka panjang bidang ketenagakerjaan dan ketrasmigrasian tahun 2010-2025 yaitu (1) meningkatkan kompetensi angkatan kerja; (2) Menciptakan hubungan industrial yang harmonis; (3) Menegakkan norma ketenagakerjaan; (4) Mengembangkan hukum ketenagakerjaan; (5) Mengembangkan Sumber Daya Manusia aparatur ketenagakerjaan. 
Lebih lanjut UU No 13 Tahun 2003 tentang ketenagakerjaan menyatakan bahwa "perlindungan terhadap tenaga kerja dimaksudkan untuk menjamin hak hak dasar tenaga kerja dan menjamin kesamaan kesempatan serta perlakuan tanpa ada diskriminasi atas dasar apapun untuk mewujudkan kesejahteraan tenaga kerja".

Salah satu kebijakan yang dikembangkan pemerintah untuk mengatasi pengangguran ini adalah dengan mendorong pengiriman tenaga kerja ke luar negeri. Kebijakan penting dalam hal ini adalah dibentuknya Badan Nasional Penempatan dan Perlindungan Tenaga Kerja Indonesia (BNP2TKI) yang langsung dibawah Presiden Republik Indonesia. Dalam kegiatan ini, BNP2TKI bekerjasama dengan berbagai Perusahaan Penggerak Tenaga Kerja Indonesia (PPTKI) yang didirikan oleh swasta yang tergabung dalam Indonesia Manpower Supler Association (IMSA) (Perpres No 81 Tahun 2006).

Mobilitas Tenaga Kerja Indonesia (TKI) ke luar negeri dapat dipandang sebagai kegiatan yang bersifat positif tetapi juga dapat berdampak negatif. Positif bagi Indonesia karena kesempatan kerja di Indonesia masih terbatas dan bagi daerah tujuan berkaitan dengan kebutuhan tenaga kerja terutama Blue Colour (tenaga kerja kasar) yang dibutuhkan untuk meningkatkan ekonomi negara (Mantra, et al, 1999: 5). Mobilitas TKI juga merupakan kegiatan negatif yang dapat mendatangkan kerugian bagi Indonesia karena beberapa daerah pengirim akan kehilangan tenaga kerja potensial yang dibutuhkan untuk membangun daerah asal.

Mobilitas TKI ini, juga terjadi di Desa Jerowaru Kecamatan Jerowaru Kabupaten Lombok Timur Nusa Tenggara Barat. Daerah tujuan utama TKI asal Desa Jerowaru adalah Malaysia, selain itu ada sebagaian kecil yang bertujuan ke Arab Saudi. Dapat dilihat dari Tabel 1. sebagai tersebut.

Tabel 1.

Data Penduduk Desa Jerowaru Kecamatan Jerowaru Kabupaten Lombok Timur yang menjadi TKI pada Tahun 2014 - 2017

\begin{tabular}{|c|c|c|c|}
\hline No & $\begin{array}{l}\text { Negara } \\
\text { Tujuan }\end{array}$ & Tahun & $\begin{array}{c}\text { Persentase } \\
\text { (\%) }\end{array}$ \\
\hline 1 & Malaysia & 847 & 94 \\
\hline 2 & $\begin{array}{l}\text { Arab } \\
\text { Saudi }\end{array}$ & 50 & 6 \\
\hline \multicolumn{2}{|c|}{ Jumlah TKI } & 897 & 100 \\
\hline
\end{tabular}

TKI asal Desa Jerowaru yang menuju Malaysia merupakan tenaga kerja kontrak, yang biasannya bersifat nonpermanen. Sifat pelaku mobilitas nonpermanen seperti semut hitam yaitu berusaha untuk membawa pendapatan yang sebanyak-banyaknya ke daerah asal, dan menggunakan seminimal mungkin di daerah tujuan. Dalam situasi seperti ini remitan mempunyai nilai ekonomi yang tinggi bagi keluarga migran maupun masyarakat di daerah asal. Jalur yang ditempuh oleh TKI asal Desa Jerowaru yang menuju ke Malaysia yaitu ada yang jalur resmi (legal) dan ada yang melalui jalur tidak resmi (ilegal). Jalur ilegal ini tidak jarang mengakibatkan timbulnya masalah-masalah 
yang merugikan migran (tenaga kerja) dan juga Malaysia sebagai negara penerima, seperti masalah keamanan, sosial, disintergrasi dan lain-lain (Desa Jerowaru, 2018). Dengan demikian maka mobilitas TKI ini harus mendapatkan perhatian dan penanganan yang lebih serius untuk mengantisipasi dampak-dampak negatif yang mungkin timbul.

\section{Metode}

Penelitian ini adalah penelitian deskriptif kualitatif dengan metode pengumpulan data pencatatan dokumen. Penelitian deskriptif adalah penelitian yang dilakukan untuk mengetahui keberadaan variabel mandiri, baik halnya satu variabel atau lebih tanpa membuat perbandingan atau dengan menghubungkan dengan variabel lainnya (variabel mandiri adalah variabel yang berdiri sendiri). Lokasi penelitian ini berada di Desa Jerowaru Kecamatan Jerowaru Kabupaten Lombok Timur. Sampel dalam penelitian ini adalah seluruh TKI yang berangkat ke Malaysia yaag tersebar pada masing-masing desa yakni 85 orang.

Jenis data yang digunakan dalam penelitian ini adalah data primer dan data sekunder. Data primer langsung diperoleh dari responden melalui kuisioner, sedangkan untuk data sekunder berasal dari Desa Jerowaru serta sumber-sumber pustaka yang ada. Teknik pengumpulan data dalam penelitian ini menggunakan observasi, wawancara, angket/kuisioner dan dokumentasi yang selanjutnya dianalisis menggunakan teknik analisis data kualitatif.

\section{Hasil dan pembahasan}

3.1 Kondisi Ekonomi Tenaga Kerja Indonesia ke Malaysia asal Desa Jerowaru Kecamatan Jerowaru Kabupaten Lombok Timur Nusa Tenggara Barat

Kondisi ekonomi tenaga kerja Indonesia ke Malaysia asal Desa Jerowaru dapat dilihat dengan menjelaskan status pemilikan rumah, pemilikan luas lahan, kepemilikan barang-barang berharga dan keadaan fisik rumah sebelum dan sesudah menjadi TKI ke Malaysia.

Tabel 2.

Satus Pemilikan Rumah Sebelum dan Sesudah Menjadi TKI Asal Desa Jerowaru Tahun 2018

\begin{tabular}{clcccc}
\hline \multirow{2}{*}{ No } & Dusun & \multicolumn{4}{c}{ Kepemilikan Rumah } \\
\cline { 3 - 6 } & & \multicolumn{3}{c}{ Milik sendiri } & Milik orang lain \\
\cline { 3 - 6 } & & Sebelum & Sesudah & Sebelum & Sesudah \\
\hline$(1)$ & $(3)$ & $(4)$ & - & $(6)$ \\
1 & Jerowaru Daye & 9 & 10 & 2 & - \\
2 & Jerowaru Barat & 13 & 15 & 1 & - \\
3 & Jerowaru Lauk & 11 & 12 & 1 & - \\
4 & Jor & 12 & 13 & 2 & - \\
5 & Montong Wasi & 6 & 8 & 2 & - \\
6 & Telong-Elong & 7 & 9 & 2 & - \\
7 & Tutuk & 5 & 6 & 2 & 2 \\
8 & Poton Bako & 4 & 4 & 2 & 2 \\
9 & Ratu & 4 & 4 & 14 & 4 \\
& Responden & 71 & 81 & $16,5 \%$ & $4,7 \%$
\end{tabular}

Sumber : Hasil Pengolahan Data Primer, 2018 
Dari Tabel 2. di atas dapat diketahui bahwa secara keseluruhan dilihat dari status kepemilikan rumah sebelum dan sesudah menjadi TKI ke Malaysia telah terjadi peningkatan. Hal ini dibuktikan dengan status pemilikan rumah milik sendiri terjadi peningkatan dan sebaliknya terjadi penurunan status pemilikan rumah milik orang lain.

Tabel 3.

Distribusi Luas Lahan Sebelum dan Sesudah Menjadi TKI ke Malaysia Asal Desa Jerowaru Tahun 2018

\begin{tabular}{|c|c|c|c|c|c|c|c|}
\hline \multirow[t]{3}{*}{ No } & \multirow[t]{3}{*}{ Dusun } & \multicolumn{6}{|c|}{ Kepemilikan Luas Lahan } \\
\hline & & \multicolumn{2}{|c|}{$<0,35$} & \multicolumn{2}{|c|}{$0,36-0,50$} & \multicolumn{2}{|c|}{$>0,51$} \\
\hline & & Sebelum & Sesudah & Sebelum & Sesudah & Sebelum & Sesudah \\
\hline (1) & (2) & (3) & (4) & (5) & (6) & (7) & (8) \\
\hline 1 & Jerowaru Daye & 8 & 8 & - & - & 2 & 2 \\
\hline 2 & Jerowaru Barat & 11 & 10 & 2 & 3 & 2 & 2 \\
\hline 3 & Jerowaru Lauk & 9 & 9 & - & - & 2 & 2 \\
\hline 4 & Jor & 9 & 8 & 2 & 2 & 3 & 4 \\
\hline 5 & Montong Wasi & 6 & 6 & - & - & 2 & 2 \\
\hline 6 & Telong-Elong & 7 & 7 & - & - & 2 & 2 \\
\hline 7 & Tutuk & 4 & 4 & 1 & 1 & 1 & 1 \\
\hline 8 & Poton Bako & 4 & 4 & - & - & 2 & 2 \\
\hline 9 & Ratu & 5 & 4 & - & - & 1 & 2 \\
\hline & Responden & 63 & 60 & 5 & 6 & 17 & 19 \\
\hline & Persentase & $74,1 \%$ & $70,5 \%$ & $5,8 \%$ & $7,0 \%$ & $20 \%$ & $22,4 \%$ \\
\hline
\end{tabular}

Berdasarkan Tabel 3. di atas dapat diketahui bahwa secara keseluruhan dilihat dari status kepemilikan luas lahan sebelum dan sesudah menjadi TKI ke Malaysia telah terjadi perubahan. Hal ini dibuktikan dengan status kepemilikan luas lahan pada kisaran $<0,35$ Ha terjadi penurunan. Namun sebaliknya, terjadi peningkatan status kepemilikan luas lahan pada kisaran 0,36 - 0,50 Ha dan >0,51 Ha.

Tabel 4.

Distribusi Pemilikan Barang-Barang Berharga Sebelum dan Sesudah Menjadi TKI ke Malaysia Asal Desa Jerowaru Tahun 2018

\begin{tabular}{|c|c|c|c|c|c|c|c|}
\hline \multirow[t]{3}{*}{ No } & \multirow[t]{3}{*}{ Dusun } & \multicolumn{6}{|c|}{ Kepemilikan Barang-Barang Berharga } \\
\hline & & \multicolumn{2}{|c|}{ Motor } & \multicolumn{2}{|c|}{ Mobil } & \multicolumn{2}{|c|}{ Perlengkapan RT } \\
\hline & & Sebelum & Sesudah & Sebelum & Sesudah & Sebelum & Sesudah \\
\hline (1) & $(2)$ & (3) & (4) & (5) & (6) & (7) & (8) \\
\hline 1 & Jerowaru Daye & 6 & 6 & - & - & 4 & 4 \\
\hline 2 & Jerowaru Barat & 11 & 9 & - & 2 & 4 & 4 \\
\hline 3 & Jerowaru Lauk & 6 & 6 & - & - & 5 & 5 \\
\hline 4 & Jor & 6 & 6 & - & - & 7 & 7 \\
\hline 5 & Montong Wasi & 3 & 3 & - & - & 5 & 5 \\
\hline 6 & Telong-Elong & 4 & 4 & - & - & 5 & 5 \\
\hline 7 & Tutuk & 3 & 3 & - & - & 3 & 3 \\
\hline 8 & Poton Bako & 3 & 3 & - & - & 3 & 3 \\
\hline 9 & Ratu & 2 & 2 & - & - & 4 & 4 \\
\hline & Responden & 45 & 43 & - & 2 & 40 & 40 \\
\hline & Persentase & $53 \%$ & $50,5 \%$ & $-\%$ & $2,3 \%$ & $47 \%$ & $47 \%$ \\
\hline
\end{tabular}

Sumber : Hasil Pengolahan Data Primer, 2018 
Berdasarkan Tabel 4. di atas dapat diketahui bahwa secara keseluruhan dilihat dari status kepemilikan barang-barang berharga sebelum dan sesudah menjadi TKI ke Malaysia telah terjadi perubahan. Hal ini dibuktikan dengan status kepemilikan barangbarang berharga berupa motor terjadi penurunan. Hal ini disebabkan oleh sebagian penduduk menjual kendaraannya berupa motor untuk digantikan dengan mobil dan terjadi peningkatan status kepemilikan barang-barang berharga berupa mobil. Namun sebaliknya, tidak terjadi peningkatan maupun penurunan status kepemilikan barangbarang berharga berupa perlengkapan rumah tangga. Hal ini mengindikasikan keberhasilan penduduk Desa Jerowaru setelah menjadi Tenaga Kerja Indonesia ke Malaysia.

Tabel 5.

Distribusi Keadaan Fisik Rumah Sebelum dan Sesudah Menjadi TKI Ke Malaysia Asal Desa Jerowaru Tahun 2018

\begin{tabular}{|c|c|c|c|c|c|c|c|c|c|c|c|c|c|c|c|c|c|}
\hline \multirow{4}{*}{ No } & \multirow{4}{*}{ Dusun } & \multicolumn{16}{|c|}{ Keadaan Fisik Rumah } \\
\hline & & \multicolumn{6}{|c|}{ Atap Rumah } & \multicolumn{4}{|c|}{ Dinding Rumah } & \multicolumn{6}{|c|}{ Lantai Rumah } \\
\hline & & \multicolumn{2}{|c|}{ Asbes } & \multicolumn{2}{|c|}{$\begin{array}{l}\text { Alang - } \\
\text { Alang }\end{array}$} & \multicolumn{2}{|c|}{ Genteng } & \multicolumn{2}{|c|}{$\begin{array}{l}\text { Batu } \\
\text { Bata }\end{array}$} & \multicolumn{2}{|c|}{ Bambu } & \multicolumn{2}{|c|}{ Semen } & \multicolumn{2}{|c|}{ Keramik } & \multicolumn{2}{|c|}{ Tanah } \\
\hline & & $\mathrm{B}$ & $\mathrm{S}$ & B & S & $\mathrm{B}$ & S & $\mathrm{B}$ & $\mathrm{S}$ & $\mathrm{B}$ & $\mathrm{S}$ & $\mathrm{B}$ & $\mathrm{S}$ & $\mathrm{B}$ & $S$ & $\mathrm{~B}$ & $\mathrm{~S}$ \\
\hline 1 & Jerowaru Daye & - & - & - & - & 10 & 10 & 10 & 10 & - & - & 10 & 5 & - & 5 & - & - \\
\hline 2 & Jerowaru Barat & 2 & - & - & - & 13 & 15 & 11 & 14 & 4 & - & 15 & 5 & - & 10 & - & - \\
\hline 3 & Jerowaru Lauk & 3 & 1 & - & - & 9 & 9 & 9 & 11 & 3 & - & 11 & 7 & - & 5 & - & - \\
\hline 4 & Jor & - & - & - & - & 13 & 13 & 9 & 14 & 5 & - & 13 & 8 & - & 6 & & \\
\hline 5 & Montong Wasi & 2 & 6 & 4 & - & 2 & 2 & 3 & 8 & 5 & - & 1 & 4 & - & 4 & 8 & - \\
\hline 6 & Telong-Elong & 1 & - & 8 & - & - & 9 & 2 & 9 & 6 & 1 & - & 4 & - & 5 & 9 & - \\
\hline 7 & Tutuk & - & - & 6 & 1 & - & 5 & 2 & 5 & 4 & 1 & - & 4 & - & 2 & 7 & - \\
\hline 8 & Poton Bako & 1 & - & 4 & 1 & 1 & 6 & 1 & 5 & 5 & 1 & - & 2 & - & 1 & 6 & 2 \\
\hline 9 & Ratu & 1 & - & 4 & 1 & 1 & 6 & 1 & 3 & 5 & 3 & - & 3 & - & 3 & 6 & - \\
\hline & Responden & 10 & 7 & 26 & 3 & 49 & 75 & 48 & 79 & 37 & 6 & 49 & 42 & - & 41 & 36 & 2 \\
\hline & Persentase & $\begin{array}{l}11 \\
7 \%\end{array}$ & $\begin{array}{c}8,2 \\
\%\end{array}$ & $\begin{array}{l}30 \\
5 \%\end{array}$ & $\begin{array}{c}3,5 \\
\%\end{array}$ & $\begin{array}{l}57, \\
6 \%\end{array}$ & $\begin{array}{l}88, \\
2 \%\end{array}$ & $\begin{array}{c}56 \\
4 \\
\%\end{array}$ & $\begin{array}{c}92, \\
9 \\
\%\end{array}$ & $\begin{array}{c}43 \\
5 \\
\%\end{array}$ & $\begin{array}{c}7,0 \\
\%\end{array}$ & $\begin{array}{c}57 \\
6 \\
\%\end{array}$ & $\begin{array}{c}49 \\
4 \\
\%\end{array}$ & - & $\begin{array}{c}48,2 \\
\%\end{array}$ & $\begin{array}{c}42, \\
3 \\
\%\end{array}$ & $\begin{array}{c}2, \\
3 \\
\%\end{array}$ \\
\hline
\end{tabular}

Sumber : Hasil Pengolahan Data Primer, 2018

Keterangan :

B : Sebelum menjadi TKI

S : Setelah menjadi TKI

Berdasarkan Tabel 5 di atas dapat diketahui bahwa secara keseluruhan dilihat dari keadaan fisik rumah sebelum dan sesudah menjadi TKI ke Malaysia telah terjadi perubahan. Hal ini dibuktikan dengan penggunaan atap rumah berupa genteng terjadi peningkatan, sebaliknya terjadi penurunan penggunaan atap rumah berupa alang-alang dan asbes. Dilihat dari penggunaan dinding rumah berupa batu-bata terjadi peningkatan, sebaliknya terjadi penurunan penggunaan dinding rumah berupa bambu. Dilihat dari penggunaan lantai rumah berupa keramik terjadi peningkatan, sebaliknya terjadi penurunan penggunaan lantai rumah berupa semen dan tanah. Hal ini mengindikasikan keberhasilan penduduk Desa Jerowaru setelah menjadi Tenaga Kerja Indonesia ke Malaysia. 
Berdasarkan hasil penelitian kondisi ekonomi TKI ke Malaysia asal Desa Jerowaru setelah melakukan mobilitas sebagai TKI ke Malaysia terjadi peningkatan ekonomi keluarganya di daerah asal dibuktikan dari status kepemilikan rumah, status kepemilikan luas lahan, status kepemilikan barang-barang berharga dan keadaan fisik rumah terjadi perubahan. Hasil penelitian ini sejalan dengan yang dilakukan oleh Saribulan (2015) di Kecamatan Mapili Kabupaten Polewali Mandar menyatakan bahwa terjadi peningkatan kondisi ekonomi keluarganya. Hal ini dapat dilihat dari kebutuhan fisik, seperti untuk memperbaiki rumah, pembelian alat-alat rumah tangga dan yang paling penting adalah bisa menyekolahkan anaknya setelah melakukan mobilitas ke Luar Negeri menjadi TKW. Hasil penelitian ini juga didukung oleh penelitian Karlina (2016) di Desa Cikedung Kecamatan Kabupaten Indramayu menyatakan bahwa pengaruh bekerja diluar negeri terhadap tinggkat ekonomi menunjukan keadaan ekonomi dari pelaku mobilitas mengalami peningkatan yang tinggi. Hasil penelitian ini juga didukung oleh penelitian Sarmita dan Suyasa (2017) di Kecamatan Kuta Selatan menunjukkan adanya kesimpulan bahwa kenaikan lama tinggal migran di daerah tujuan cenderung menaikkan status ekonominya.

\subsection{Faktor-Faktor Yang Mendorong TKI Asal Desa Jerowaru Untuk Mengadakan Mobilitas Ke Malaysia}

Adapun hasil penelitian terdapat dua faktor yang mendorong TKI asal Desa Jerowaru melakukan mobilitas yaitu sedikitnya lapangan pekerjaan di daerah asal dan pendapatan yang minim (rendah). Secara lebih rinci alasan TKI melakukan mobilitas ke Malaysia dan tidak bisa dipisahkan dari faktor negatif dari daerah asal dapat dilihat pada Tabel 6. sebagai berikut:

Tabel 6

Alasan-Alasan yang Mendorong TKI Asal Desa Jerowaru untuk Mengadakan Mobilitas ke Malaysia Tahun 2018

\begin{tabular}{|c|c|c|c|c|c|}
\hline \multirow[t]{2}{*}{ No } & \multirow[t]{2}{*}{ Dusun } & \multicolumn{3}{|c|}{ Alasan - Alasan Yang Mendorong } & \multirow[b]{2}{*}{$\begin{array}{l}\text { Tidak ada biaya } \\
\text { untuk memenuhi } \\
\text { kebutuhan sehari- } \\
\text { hari dan } \\
\text { kebutuhan lain- } \\
\text { lainnya }\end{array}$} \\
\hline & & $\begin{array}{l}\text { Tidak ada } \\
\text { biaya untuk } \\
\text { sekolah bagi } \\
\text { anak-anaknya }\end{array}$ & $\begin{array}{l}\text { Tidak ada biaya } \\
\text { untuk membeli } \\
\text { kendaraan }\end{array}$ & $\begin{array}{l}\text { Tidak ada } \\
\text { biaya untuk } \\
\text { membangun/m } \\
\text { emperbaiki } \\
\text { rumah }\end{array}$ & \\
\hline 1 & Jerowaru Daye & 3 & 3 & 3 & 1 \\
\hline 2 & $\begin{array}{l}\text { Jerowaru } \\
\text { Barat }\end{array}$ & 4 & 5 & 1 & 5 \\
\hline 3 & Jerowaru Lauk & 5 & 3 & 2 & 1 \\
\hline 4 & Jor & 4 & 5 & 2 & 3 \\
\hline 5 & Montong Wasi & 3 & 2 & - & 3 \\
\hline 6 & Telong-Elong & 4 & 3 & 1 & 1 \\
\hline 7 & Tutuk & 2 & 2 & 1 & 1 \\
\hline 8 & Poton Bako & 2 & 2 & - & 2 \\
\hline 9 & Ratu & 3 & 1 & - & 2 \\
\hline & Responden & 30 & 26 & 10 & 19 \\
\hline & Persentase & $35,2 \%$ & $30,5 \%$ & $11,7 \%$ & $22,3 \%$ \\
\hline
\end{tabular}

Sumber : Hasil Pengolahan Data Primer, 2018 
Dari Tabel 6. di atas dapat dilihat bahwa faktor pendorong sebagian besar penduduk Desa Jerowaru melakukan mobilitas ke Malaysia sebagai TKI adalah sebagai beikut, yaitu karena alasan tidak ada biaya untuk sekolah, tidak ada biaya untuk membeli kendaraan, tidak ada biaya untuk membangun/memperbaiki rumah dan tidak ada biaya untuk memenuhi kebutuhan sehari-harinya dan kebutuhan lain-lainnya. Selain faktor pendorong dari daerah asal ada juga faktor pendorong dari daerah tujuan yang mempengaruhi TKI asal Desa Jerowaru melakukan mobilitas ke Malaysia yaitu terdapat banyaknya lapangan pekerjaan dan pendapatan yang lebih memadai (tinggi) dibandingkan di daerah asal.

Berdasarkan hasil penelitian bahwa faktor-faktor yang pendorong tenaga kerja asal Desa Jerowaru untuk melakukan mobilitas ke Malaysia sebagai TKI disebabkan oleh beberapa faktor, yaitu: (1) karena tidak ada biaya untuk sekolah bagi anak-anaknya; (2) karena tidak ada biaya untuk membeli kendaraan; (3) karena tidak ada biaya untuk memenuhi kebutuhan sehari-hari, (4) karena tidak ada biaya untuk membangun/memperbaiki rumah, ditambah dengan sedikit lapangan pekerjaan di daerah asal dan pendapatan yang minim (rendah) serta sempitnya luas lahan yang dimiliki di daerah asal. Hasil penelitian ini juga di dukung oleh adanya studi empirik tentang migrasi oleh Rhoda (1989) dalam (Mantra, 1999) yang menyatakan berbagai survei menunjukan bahwa migrasi didorongkan oleh pertimbangan ekonomi dan merupakan faktor utama yang meliputi : 1 . Pekerjaan dan pengangguran pertanian, 2. Sempitnya lahan pertanian dan kemiskinan. Kemudian diperkuat oleh hasil penelitian yang dilakukan Mantra (1986) terhadap 431 migran sirkuler di perkotaan Yogyakarta, 400 migran sirkuler di perkotaan Bandung dan 401 migran di perkotaan Samarinda, tampak bahwa alasan ekonomi sangat dominan baik di Yogyakarta $(79,9 \%)$, Bandung $(71,1 \%)$ maupun Samarinda $(66,1 \%)$.

\subsection{Kontribusi/sumbangan TKI Ke Malaysia Terhadap Kondisi Ekonomi Rumah Tangga di Daerah Asal}

Untuk lebih jelasnya mengenai hasil keseluruhan rekapitulasi sumbangan kontribusi (remitan) yang dikirim TKI ke Malaysia untuk di daerah asal (Desa Jerowaru) dapat dilihat pada tabel 7. sebagai berikut.

Tabel 7.

Rekapitulasi Sumbangan/Remitan TKI ke Malaysia Asal Desa Jerowaru Untuk Keluarga di Daerah

\begin{tabular}{clccccc} 
& & \multicolumn{3}{c}{ Asal Tahun 2018 } & & \\
\cline { 3 - 5 } No & Sektor Pekerjaan & \multicolumn{2}{c}{ Kontribusi/remitan (\%) } & Responden & Persentase \\
\cline { 3 - 5 } & & $0-33$ & $34-67$ & $68-100$ & & \\
\cline { 3 - 5 }$(1)$ & $($ Kecil) & $($ Sedang) & $($ Besar) & & \\
1 & Buruh Bangunan & $(3)$ & $(4)$ & $(5)$ & $(6)$ & $(7)$ \\
2 & Pembantu Rumah tangga & - & $69,2 \%$ & $30,7 \%$ & 13 & $100 \%$ \\
3 & Perkebunan & - & $70 \%$ & $30 \%$ & 10 & $100 \%$ \\
& $\quad$ Jumlah & & $74,1 \%$ & $25,8 \%$ & 85 & $100 \%$ \\
\hline
\end{tabular}

Sumber : Hasil Pengolahan Data Primer, 2018 
Berdasarkan Tabel 7 dapat diketahui bahwa kontribusi yang diberikan TKI untuk keluarganya di daerah asal didominasi oleh kontribusi sedang. Adapaun rincian kontibusinya berdasarkan sektor pekerjaannya, yaitu para TKI yang bekerja di sektor perkebunan yang lebih banyak memberikan kontribusi sedang dan diikuti oleh sektor pembantu rumah tangga dan buruh bangunan, sedangkan kontribusi besar lebih banyak di sumbangkan oleh sektor pekerjaan buruh banggunan dan pembantu rumah tangga serta diikuti oleh sektor perkebunan. Hal ini mengindikasikan keberhasilan penduduk setelah melakukan mobilitas ke Malaysia sebagai TKI.

Berdasarkan hasil perhitungan dengan metode deskriptif atau membandingkan pendapatan total rumah tangga dengan kontribusi (remitan) yang diberikan oleh TKI, diperoleh bahwa persentase remitan/sumbangan yang diberikan oleh TKI untuk ekonomi keluarganya di daerah asal didominasi oleh kontribusi sedang sebanyak 74,1 $\%$ dan 25,8 \% dengan kontribusi besar. Rekapitulasi kontribusi yang diberikan TKI untuk keluarganya di daerah asal sangat membantu meningkatkan kondisi ekonomi rumah tangga di daerah asal dan dipergunakan untuk berbagai keperluan keluarganya baik untuk memenuhi kebutuhan pokok yaitu biaya pembelian beras dan jenis pangan lainnya, biaya pendidikan anak-anaknya, biaya membangun/memperbaiki rumah, biaya membeli kendaraan dan untuk keperluan rumah tangga lainnya. Hasil penelitian ini didukung oleh temuan Saefullah (1983) di Jawa Barat yaitu sebagian besar rumah tangga di daerah asal menggunakan pendapatan yang diperoleh dari daerah tujuan mobilitas untuk keperluan sehari-hari, baru disusul untuk biaya pendidikan anakanaknya, biaya memperbaiki rumah tinggal, modal usaha dan biaya keperluan lainnya.

Berdasarkan data yang dikumpulkan dalam penelitian Mantra 1989 sampai 1990, lebih dari 90 \% responden menyatakan bahwa kehidupan ekonomi rumah tangga mereka menjadi lebih baik setelah bekerja di luar desa asal, yang didukung oleh hasil penelitian lain di daerah pedesaan Kabupaten Garut, Kabupaten Tasikmalaya, Kabupaten Ciamis oleh Saefullah et al (1983), terdapat 85 \% responden mempunyai pendapat bahwa meningkatnya kehidupan sosial ekonomi rumah tangga mereka sebagai akibat bekerja di luar daerah asal.

\section{Simpulan dan saran}

Berpijak pada hasil temuan dalam pembahasan yang telah dilakukan, dapat disimpulkan tiga hal. Pertama, kondisi ekonomi TKI asal Desa Jerowaru ke Malaysia sebelum dan sesudah menjadi TKI ke Malaysia secara keseluruhan telah terjadi peningkatan kondisi ekonomi keluarganya di daerah asal (Desa Jerowaru) dilihat dari indikator - indikator sebagai berikut; (1) status kepemilikan rumah; (2) status kepemilikan luas lahan (3) status kepemilikan barang-barang berharga (4) keadaan fisik rumah. Kedua, faktor yang mendorong TKI asal Desa Jerowaru untuk melakukan mobilitas sebagai tenaga kerja ke Malaysia adalah sebagai berikut; (1) karena disebabkan oleh tidak ada biaya untuk sekolah bagi anak-anaknya; (2) karena tidak ada biaya untuk membeli kendaraan; (3) karena tidak ada biaya untuk memenuhi kebutuhan sehari-hari dan kebutuhan lain-lainnya; (4) karena tidak ada biaya untuk membangun/memperbaiki rumah dan ditambah dengan sedikitnya lapangan pekerjaan 
di daerah asal dan pendapatan yang minim (rendah), serta sempitnya luas lahan yang dimiliki di daerah asal. Ketiga, konribusi (remitan) yang diberikan oleh Tenaga Kerja Indonesia untuk ekonomi keluarganya di daerah asal didominasi oleh kontribusi sedang sebanyak 74,1 \% dan 25,8 \% dengan kontribusi besar. Pendapatan yang dibawa TKI Malaysia asal Desa Jerowaru dari daerah tujuan ke daerah asal dipergunakan untuk keperluan rumah tangga dan kehidupan sehari-hari.

Berdasarkan hasil penelitian yang telah dilakukan, dapat dikemukakan saransaran agar Pemerintah (Desa Jerowaru, Camat Jerowaru dan Kabupaten Lombok Timur NTB) dapat mengupayakan usaha untuk penciptaan kesempatan kerja dengan kegiatan industri rumah tangga perlu dilaksanakan. Oleh karena itu pemanfaatan potensi desa secara optimal untuk meningkatkan pendapatan penduduk sangat penting. Untuk menanggulangi masalah arus gerakan penduduk dari desa ke daerah lain semakin meningkat, makan pengambilan keputusan untuk melakukan mobilitas ke luar negeri merupakan salah satu langkah yang tepat. Agar kebutuhan para anggota keluarga di daerah asal dapat dipenuhi. Untuk itu perlu adanya pemikiran dan penanganan dari pihak yang berwewenang tentang hal-hal yang dapat menunjang kegiatan pengiriman TKI ke luar negeri.

\section{Daftar Rujukan}

Ananta, Aris. 1995. Ciri Demografi Kualitas Penduduk Dalam Pembangunan Ekonomi. Jakarta: Lembaga Demografi FEUI.

Badan Pusat Statistik. 1990-2017. Tentang Jumlah Pengangguran di Indonesia. Jakarta. diakses dari: http://www.bps.go.ig/. diakses pada 2 November 2018.

Karlina, Eli. 2016. Pengaruh Bekerja di Luar Negeri Terhadap Tingkat Ekonomi dan Perceraian (Studi Kasus di Desa Cikedung Kecamatan Cikedung Kabupaten Indramayu). Skripsi. Jakarta: Jurusan Pendidikan Ilmu Sosial. FITK. UIN Syarif Hidayatullah Jakarta.

Mantra, Ida Bagoes. 1999. Mobilitas Penduduk Sirkuler. Kertas Kerja Nomor 30 Pusat Penelitian Kependudukan. Yogyakarta: Universitas Gajah Mada.

Mantra, Ida Bagoes. 1999. Mobilitas Tenaga Kerja Ke Malaysia. Seri Laporan Nomor 81 Pusat Penelitian Kependudukan. Yogyakarta : Universitas Gajah Mada.

Saefullah, H. Asep Djadja.1983. Mobilitas Penduduk dan Perubahan di Pedesaan: Studi Kasus di Jawa Barat. Prisma 7, Juli 1983. Indonesia: PT. Pustaka LP3ES.

Saribulan, Andi. 2015. Kehidupan Sosial Ekonomi Keluarga Tenaga Kerja Wanita (Studi Kasus Pada 5 (Lima) Keluarga di Kecamatan Mapili Kabupaten Polewali Mandar). Skripsi. Makasar: Program Studi Sosiologi. FIS. UNM.

Sarmita, I. Made, dan P. Wayan Artha Suyasa. Penyesuaian Diri Migran Sirkuler Asal Jawa Di Kecamatan Kuta Selatan. Proceeding Senari 5 (2017) : 80-87. Terdapat pada: (http://eproceeding.undiksha.ac.id/index.php/senari/article/view/920). Diakses pada 19 Desember 2018.

Profil Desa Jerowaru. 2018. Tentang Jumlah Tenaga Kerja Indonesia dan Jumlah Penduduk 